\title{
Mechanistic insight into sevoflurane-associated developmental neurotoxicity
}

\author{
Mingyang Sun $\cdot$ Zhongcong Xie $\cdot$ \\ Jiaqiang Zhang $\mathbb{D} \cdot$ Yufang Leng
}

Received: 21 September 2021 / Accepted: 21 October 2021 / Published online: 12 November 2021

(C) The Author(s) 2021

\begin{abstract}
With the development of technology, more infants receive general anesthesia for surgery, other interventions, or clinical examination at an early stage after birth. However, whether general anesthetics can affect the function and structure of the developing infant brain remains an important, complex, and controversial issue. Sevoflurane is the most-used anesthetic in infants, but this drug is potentially neurotoxic. Short or single exposure to sevoflurane has a weak effect on cognitive function, while long or repeated exposure to general anesthetics may cause cognitive dysfunction. This review focuses on the
\end{abstract}

\section{Sun}

The First School of Clinical Medicine, Lanzhou University, Lanzhou, Gansu, People's Republic of China 730000

M. Sun $\cdot$ J. Zhang ( $\bowtie)$

Department of Anesthesiology and Perioperative Medicine, Center for Clinical Single Cell Biomedicine, Henan Provincial People's Hospital, People's Hospital of Zhengzhou University, Zhengzhou, Henan,

People's Republic of China 450003

e-mail: jqzhang@henu.edu.cn

\section{Z. Xie}

Department of Anesthesia, Critical Care and Pain Medicine, Massachusetts General Hospital and Harvard Medical School, Boston, MA, USA

\section{Y. Leng $(\bowtie)$}

Day Surgery Center, The First Hospital of Lanzhou University, Lanzhou, Gansu, People's Republic of China 730000

e-mail: lengyf_lzu@126.com mechanisms by which sevoflurane exposure during development may induce long-lasting undesirable effects on the brain. We review neural cell death, neural cell damage, impaired assembly and plasticity of neural circuits, tau phosphorylation, and neuroendocrine effects as important mechanisms for sevoflurane-induced developmental neurotoxicity. More advanced technologies and methods should be applied to determine the underlying mechanism(s) and guide prevention and treatment of sevofluraneinduced neurotoxicity.

Highlights 1. We discuss the mechanisms underlying sevoflurane-induced developmental neurotoxicity from five perspectives: neural cell death, neural cell damage, assembly and plasticity of neural circuits, tau phosphorylation, and neuroendocrine effects.2. Tau phosphorylation, IL-6, and mitochondrial dysfunction could interact with each other to cause a nerve damage loop.3. miRNAs and lncRNAs are associated with sevoflurane-induced neurotoxicity.

Keywords Sevoflurane Y Young brain - Neural cell damage $\cdot$ Neural circuit $\cdot$ Tau phosphorylation . Neuroendocrine 


\section{Introduction}

With the progress of medical technology, greater numbers of infants receive surgery, interventions, or examination under general anesthesia at an early stage after birth. Consequently, the neurotoxicity of general anesthesia is receiving increasing attention. The US Food and Drug Administration released a warning of drug safety in December 2016, which stated that 11 commonly used sedative and anesthetic medications had potential neurotoxic effects in pregnant women during the third trimester and children under the 3 years of age (2016). This warning indicates the need for studies to delineate any potential adverse neurodevelopmental consequences on children.

Sevoflurane is an agentia for inhalational induction due to its low blood-gas solubility and rapid onset, particularly in pediatric anesthesia. Yet, repeated or prolonged exposure to sevoflurane is neurotoxic in the developing brain in animal studies. For example, in mice, maternal anesthesia with sevoflurane induces social interaction deficits in the offspring (Chen et al., 2021). Monkeys exposed to sevoflurane anesthesia in infancy have increased anxiety-related behaviors during adolescence, (Raper et al., 2015), and early repeated sevoflurane anesthesia in monkey infancy results in an anxious phenotype which persists over time (Raper et al., 2018). In mice, neonatal exposure to sevoflurane anesthesia may raise the risk of cognitive dysfunction in adults (Dai et al., 2020), and repeated neonatal sevoflurane exposure induces attention-deficit/hyperactivity-disorder-like impulsive behavior in later adulthood (Xie et al., 2020).

Findings in humans are less conclusive. Children under 3 years of age who underwent surgery were
$60 \%$ more likely to be subsequently diagnosed with developmental and behavioral disorders than children accepted no surgery (DiMaggio et al., 2011), and anesthesia was considered to be a potential independent risk factor. Most recently, both of the General Anesthesia vs. Spinal (GAS) Anesthesia and Pediatric Anesthesia and Neurodevelopment Assessment (PANDA)studies involved formal neurodevelopmental testing, showed that there is no correlation between single and transient general anesthesia and poor neurodevelopmental outcome. (Davidson et al., 2016; Sun et al., 2016). However, in the Mayo Anesthesia Tolerability in Kids study, there were subtle declines in fine-motor coordination and processing speed that might impede learning after sevoflurane exposure, and children one or more times exposed to sevoflurane had difficulty with reading (Warner et al., 2018). Furthermore, a comparison of 46 neurodevelopmental outcomes in 13,433 children showed that multiple exposures to sevoflurane are associated with an increased risk of poor motor function, lower hand dexterity, and lower social scores (Walkden et al., 2020).

Together, existing findings from both animal studies and clinical studies raise concern about the potential neurotoxic effect of sevoflurane in children, particularly for any interference with critical processes in brain development. In this review, we discuss the mechanisms by which sevoflurane may alter neurodevelopment from five aspects: neural cell death, neural cell damage, assembly and plasticity of the neural circuit, tau phosphorylation, and neuroendocrine effects (Fig. 1).
Fig. 1 The mechanisms of sevoflurane may alter neurodevelopment from five aspects: neural cell death, neural cell damage, assembly and plasticity of the neural circuit, tau phosphorylation, and neuroendocrine effects

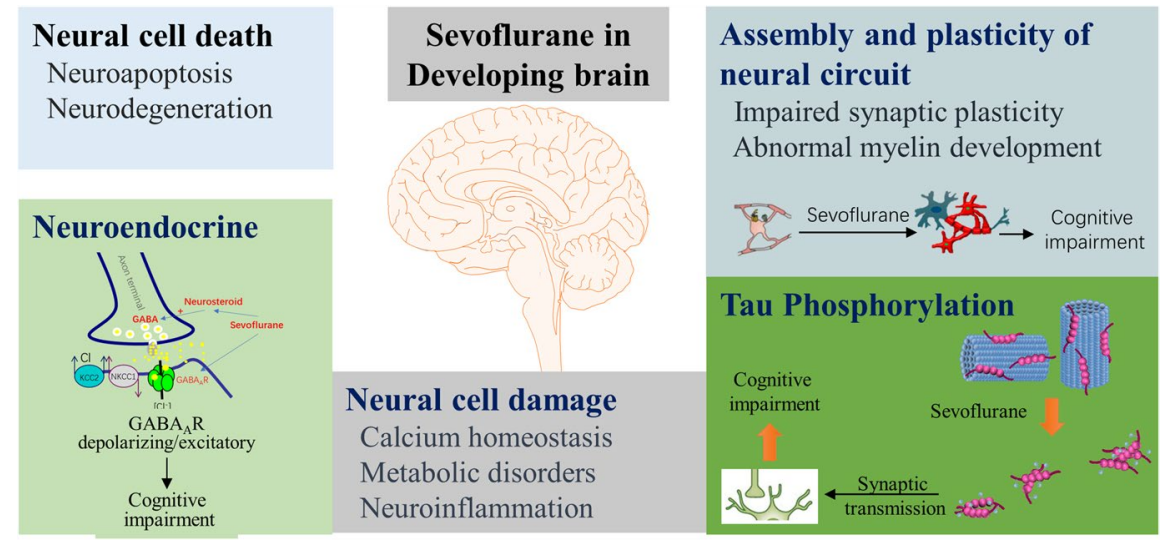




\section{Neural cell death}

Neuroapoptosis is the main pathway leading to neural cell death

Most pre-clinical studies of sevoflurane focus on apoptosis as the leading cause of neurotoxicity. During development, this type of programmed cell death is normal, but prolonged exposure to sevoflurane in young animals could lead to the rate of neuroapoptosis increasing 50-fold (McCann and de Graaff, 2017). Sevoflurane exposure causes millions of otherwise healthy and functional neurons to commit to apoptotic-programmed cell death (Dikranian et al., 2001). Indeed, this exposure can cause neuroapoptosis through several different molecular mechanisms, and it is not yet clear which mechanism is preferred. Two major signaling pathways can promote apoptosis: the intrinsic and the extrinsic pathways (Yon et al., 2005).

The intrinsic pathway is initiated in response to signals from within the cell, resulting in a decreasing anti-apoptotic (such as BCL-2, MCL1, BCL-XL) and pro-apoptotic (BAX/BAK) ratio, which induces mitochondrial outer membrane permeabilization (MOMP). MOMP promoted cytochrome $\mathrm{C}$ release from the mitochondria and activated caspase- 9 cleavage (Green and Llambi, 2015; Liu et al., 2020; Yon et al., 2005). Phosphorylation of antiapoptotic MCL1 can be activated by stress and mitotic kinases such as AMP-activated protein kinase (MAPK), p38 MAPK, casein kinase II, Jun amino-terminal kinase (JNK) (Wertz et al., 2011), and growth factor and phosphoinositide 3-kinase (PI3K)-AKT-glycogen synthase kinase (GSK) 3 signaling (Maurer et al., 2006). BH3only proteins (sensitizers or derepressors) promote MOMP proteins, BCL-2. JNK, extracellular signalregulated kinase 1 and 2 (ERK1/2) by antagonizing antiapoptotic and p53 are involved in apoptosis, and their activation can promote MOMP and induce intrinsic apoptosis (Green and Llambi, 2015). Neonatal sevoflurane exposure in rodents profoundly decreases the histone acetyltransferase activity of cyclic adenosine monophosphate (cAMP) response element-binding (CREB) protein in the hippocampus (Dong et al., 2020a). CREB-binding protein acetylation is implicated in learning (Barrett et al., 2011; Maddox et al., 2013), and CREB pathway inactivation may downregulate the transcription of anti-apoptotic genes and increase the levels of pro-apoptotic factors (Lee et al., 2013), in turn, decreasing the anti-apoptotic (BCL-2, MCL1, BCL-XL)/pro-apoptotic (BAX/ $\mathrm{BAK})$ ratio, promoting MOMP, and inducing intrinsic apoptosis.

Sevoflurane induces neuroapoptosis in the developing brains of young rats via the brain-derived neurotrophic factor (BDNF)-modulated apoptotic cascade (Hu et al., 2019; Yu et al., 2020b), which also results in a decreasing anti-apoptotic/pro-apoptotic ratio, promoting MOMP, and inducing intrinsic apoptosis. Sevoflurane exposure in the developing brain could induce neuroapoptosis by activating the JNK/c-JUN/AP-1 signaling pathway (Bi et al., 2018), activation/phosphorylation of ERK1/2 via $\beta$-arrestin 1 and 2/metabotropic glutamate receptor 7 (Wang et al., 2016a, b), activation/phosphorylation of the ERK1/2-NRF2/BACH1 signaling pathway (Yang et al., 2020a), activation/phosphorylation of ERK1/2MAPK signaling (Wang et al., 2016a, 2013b), and activation/phosphorylation of the PI3K/AKT signaling pathway (Li et al., 2017a), which can also decrease the anti-apoptotic/pro-apoptotic ratio, promote MOMP, induce intrinsic apoptosis, and cause cognitive decline in adolescence.

Repeated sevoflurane anesthesia treatment in neonatal rats also increases the density of $\mathrm{NeuN}+$ /caspase- $3+$ cells, which in the hippocampal dentate gyrus, induces caspase- 3 activation, and increases BAX levels. It also reduces levels of BCL-2 in adolescent rats, which decreases the ratio of BCL-2/ BAX, promotes MOMP, induces intrinsic apoptosis, and causes cognitive decline in adolescence. In clinical studies, sevoflurane exposure increases the mRNA expression levels of caspase-3, superoxide dismutase 1 , and glutathione peroxidase gene 1 in neural stem cells (NSCs) in postoperative blood samples and reduces cell density and cell viability of NSCs in postoperative serum in children less than 3 years old (Zhou et al., 2018). Long noncoding RNAs (lncRNA) expression profiles in the developing mouse hippocampus indicate that sevoflurane exposure upregulates IncRNAs, likely induces over-expression of BCL2L11 and BAX, but decreases BCL-2, which eventually promotes mitochondria-mediated apoptosis (Chen et al., 2016). Sevoflurane induces neuronal apoptosis in the immature brain mostly by initiating the intrinsic pathway. The endogenous 
apoptosis pathway could be targeted to treat neurotoxicity caused by sevoflurane in the developing brain (Fig. 2).

The extrinsic pathway can be activated via tumor necrosis factor (TNF) receptors, which increase FAS (also known as CD95, which is a death receptor) protein and activate caspase- 8 . Cell death induced by death receptors is generally crucial to immune system function and homeostasis (Green and Llambi, 2015). Bid is activated by caspase- 8 -mediated cleavage, and Bid in turn promotes MOMP by activating BAX and BAK. Sevoflurane significantly increases the expression of FAS protein in young mice (Song et al., 2015), which activates caspase- 8 and induces neuroapoptosis. However, sometimes sevoflurane-induced apoptosis may be independent of death receptor signaling (Loop et al., 2005). Furthermore, the extrinsic and intrinsic pathways may at times interact with each other to cause apoptosis.

Sevoflurane also induces neuroapoptosis through modulation of reactive oxygen species (ROS) production (Jin et al., 2013), proopiomelanocortin (Wei et al., 2019b), and $\beta$-amyloid protein (Lu et al., 2010), shifting the pentose phosphate pathway to the glycolytic pathway (Liu et al., 2019a). This also affects the receptor-interacting protein (RIPK)1/RIPK3 signaling pathway (Xu et al., 2021) and the PERK-eIF2a ATF4- CHOP axis of the endoplasmic reticulum (ER) stress signaling pathway (Liu et al., 2017a). The increasing intracellular ROS results in DNA damage (Piao et al., 2020), and disruption of intracellular calcium homeostasis is also observed (Yang and Wei, 2017). Neuroapoptosis is an important mechanism of developmental neurotoxicity induced by sevoflurane. Inhibiting the neuroapoptosis pathway could be a potential targeted intervention for neurotoxicity induced by sevoflurane in the developing brain.

Neurodegeneration is the pathological basis of many cognitive disorders

Neurodegeneration underlies many cognitive disorders. In some studies, sevoflurane exposure is reported to cause neurodegenerative changes. Damage from these changes may be more widespread than initially assumed, and understanding the extent of this damage is crucial for identifying the mechanisms of and treatments for anesthesia-related neurotoxicity (Burks et al., 2020). In the pathogenesis of neurodegenerative disorders, ER stress plays a critical role (Hetz and Saxena, 2017). Sevoflurane exposure for the developing brain increases protein tyrosine phosphatase $1 \mathrm{~B}$, located in the ER, and triggers ER stress that leads to neurodegenerative changes (Liu et al., 2019b, 2017a; Zhu et al., 2017). Sevoflurane also induces neurodegeneration through restoring cAMP and activating the $\mathrm{CAMP} / \mathrm{CREB}$ signaling pathway in the developing hippocampus (Chen et al., 2020; Huang et al., 2021). Abnormal cAMP signal is an important factor in neurodegenerative changes. The methyl-cytosine-phosphate-guanine-binding protein 2/CREB signaling pathway downregulates BDNF,

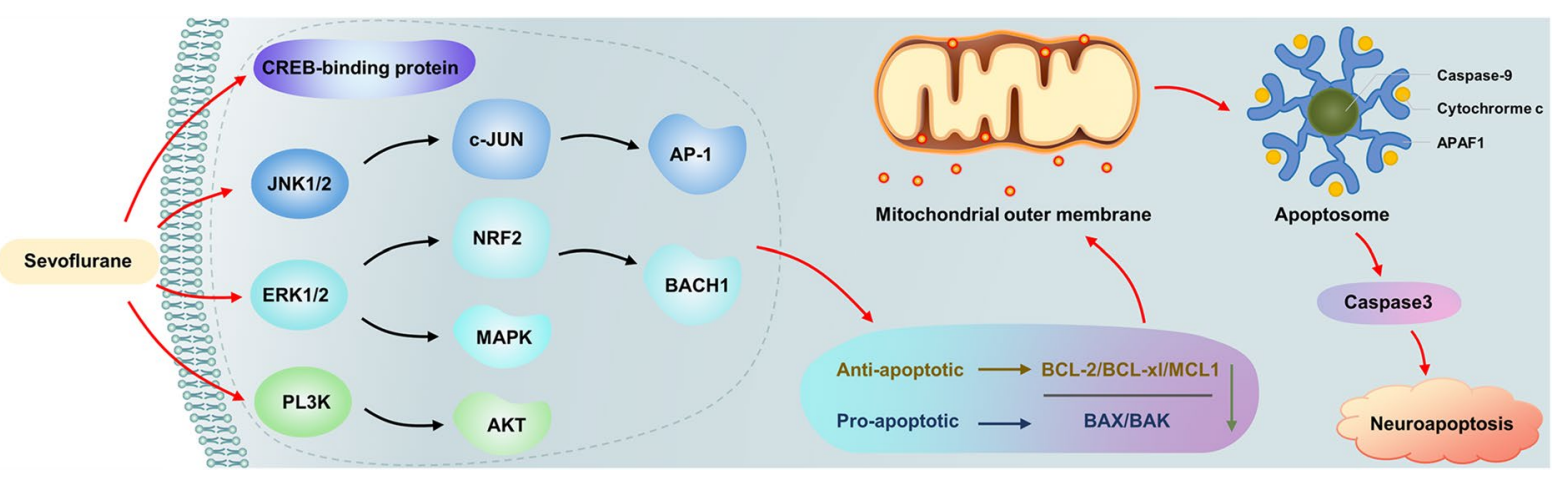

Fig. 2 Sevoflurane exposure in the developing brain could induce neuroapoptosis via the JNK/c-JUN/AP-1 axis, ERK1/2 MAPK axis, ERK1/2-NRF2/BACH1axis, PI3K/AKT axis, and CREB inactivation, which may downregulate the transcription of anti-apoptotic genes (BCL-2, BCL-XL, MCL1) and increase the levels of pro-apoptotic factors (BAX/BAK). This induces mitochondrial outer membrane permeabilization, promoting release of cytochrome $\mathrm{C}$ from the mitochondria, activating caspase- 9 cleavage and informed apoptosome, resulting in caspase 3 activation and neuroapoptosis 
which inhibits the level of sirtuin 1(SIRT1) (Tang et al., 2020). Abnormal reduction of SIRT1 is also associated with neurodegenerative diseases. Sevoflurane significantly upregulates SIRT 2 in the neonatal rat hippocampus, which promotes pro-inflammatory/ M1-related markers in microglia and activated microglia (Wu et al., 2020c). Microglia activation also has been implicated in neurodegenerative disease (Yeh et al., 2017). Multiple exposures to sevoflurane enhance histone deacetylase 6 (HDAC6) expression and activity in the developing hippocampus ( $\mathrm{Li}$ et al., 2019a), and HDAC6 overexpression plays a very important role in neurodegenerative changes. A $3 \%$ sevoflurane exposure in neonatal induces abnormal lncRNA and microRNA (miRNA) expression profiles. The dysregulated lncRNAs/mRNAs were able to formulate wide molecular networks that might contribute to neurodegenerative signaling pathways, resulting in impaired long-term memory (Jiang et al., 2021b). Iron is essential for normal neuronal function; however, excess iron is implicated in several neurodegenerative diseases. Sevoflurane exposure disturbs iron homeostasis and causes iron overload in the hippocampus, which contributes to neurodegenerative diseases (Wu et al., 2020a). Protein aggregates and mitochondria dysfunction represent key pathological hallmarks shared by most neurodegenerative diseases. Autophagic flux, the difference between autophagosome formation and cargo clearance by lysosomes, is concerned of neurodegenerative diseases development (Budini et al., 2017; Heras-Sandoval et al., 2014; Klionsky et al., 2016; Ravikumar et al., 2005). LC3, the most widely monitored autophagyER-related protein, is commonly used as a marker of autophagy. The degradation of p62 in autolysosomes suggested as an indicator of autophagy activation (Klionsky et al., 2016). Sevoflurane increases the levels of microtubule-associated protein light chain 3II protein (LC3-II), beclin-1, and the ratio of LC3II/LC3-I and decreases the levels of sequestosome 1 and p62 (Wei et al., 2019a; Xu et al., 2018) via suppression of phospho-protein kinase $\mathrm{B} /$ protein kinase $\mathrm{B}$ (p-AKT/AKT) and mammalian target of rapamycin (mTOR) (Li et al., 2017b) in the developing brain, inducing mitochondrial dysfunction and neurodegeneration. Repeated exposure of neonatal mice to $3 \%$ sevoflurane induces tau protein phosphorylation ( $\mathrm{Yu}$ et al., 2020a), which leads to tau accumulation and the formation of neurofibrillary tangles, a hallmark pathology in neurodegenerative brains, suggesting that tau plays a critical role in neurodegeneration (Pirscoveanu et al., 2017; Yang and Wang, 2018). Neurodegenerative changes caused by neonatal sevoflurane exposure may be involved in a variety of pathways, but the exact mechanism is not clear, and further investigation is needed. (Fig. 3).

\section{Neural cell damage}

Calcium homeostasis deregulation can lead to neural cell damage

Calcium plays a vital role in human physiology, particularly in the central nervous system (CNS). Precise maintenance of $\mathrm{Ca}^{2+}$ levels is vital for normal cell function, and calcium homeostasis deregulation can lead to neuronal cell damage. ER is the main source of intracellular calcium release in neurons; it plays a very important role in the maintenance of intracellular calcium homeostasis (Wei and Xie, 2009). In the mitochondrial matrix, proper $\mathrm{Ca}^{2+}$ levels tightly regulate oxidative phosphorylation activity, which maintains the rate of adenosine triphosphate (ATP) production. However, if excess $\mathrm{Ca}^{2+}$ was taken up by mitochondria, derived from the increased cytosolic $\mathrm{Ca}^{+}$or excessive $\mathrm{Ca}^{2+}$ transfer from the ER, mitochondrial respiration can be impaired, which leads to enhanced production of ROS, impaired mitochondrial membrane permeabilization, and reduced ATP production, possibly with subsequent cell damage (Calvo-Rodriguez and Bacskai, 2021; Marchi et al., 2018; Mendes et al., 2005). Sevoflurane exposure induces a significant decrease of calcium concentrations in the ER via excessive IP3 receptors activation, the $\mathrm{Ca}^{2+}$ in the cytosol, and mitochondrial accompanied by a subsequent significant increase (Yang et al., 2008). Mitochondrial $\mathrm{Ca}^{2+}$ overload leads to mitochondrial respiration impairment, ROS activation, ATP reduction, and MOMP, which induce neural cell damage and apoptosis (Danese et al., 2017; Yang and Wei, 2017). Exposure to 2\% sevoflurane at neonatal ages upregulates $\mathrm{Ca}^{2+}$-activated potassium channel type 2 (SK2s) in the CA1 region, which has persistent detrimental effects on long-term depression (LTD) and long-term potentiation (LTP) (Yu et al., 2018), and sevoflurane disrupts astrocyte $\mathrm{Ca}^{+}$homeostasis, which downregulates ezrin. The reduction of 
Fig. 3 Sevoflurane could induce neurodegenerative in the developing brain through multiple signaling pathways such as PTP-1B/ ER axis, CREB/BDNF/ SIRT1 axis, SIRT 2/microglia activation, and HDAC6 overexpression. Sevoflurane exposure suppressed p-AKT/AKT and mTOR, increasing the level of Beclin-1 and LC3-II/LC3-I and decreasing the levels of sequestosome 1 and p62, which induce activation of autophagy. Autophagy could induce neurodegenerative, which involved in sevoflurane-induced neurodegenerative

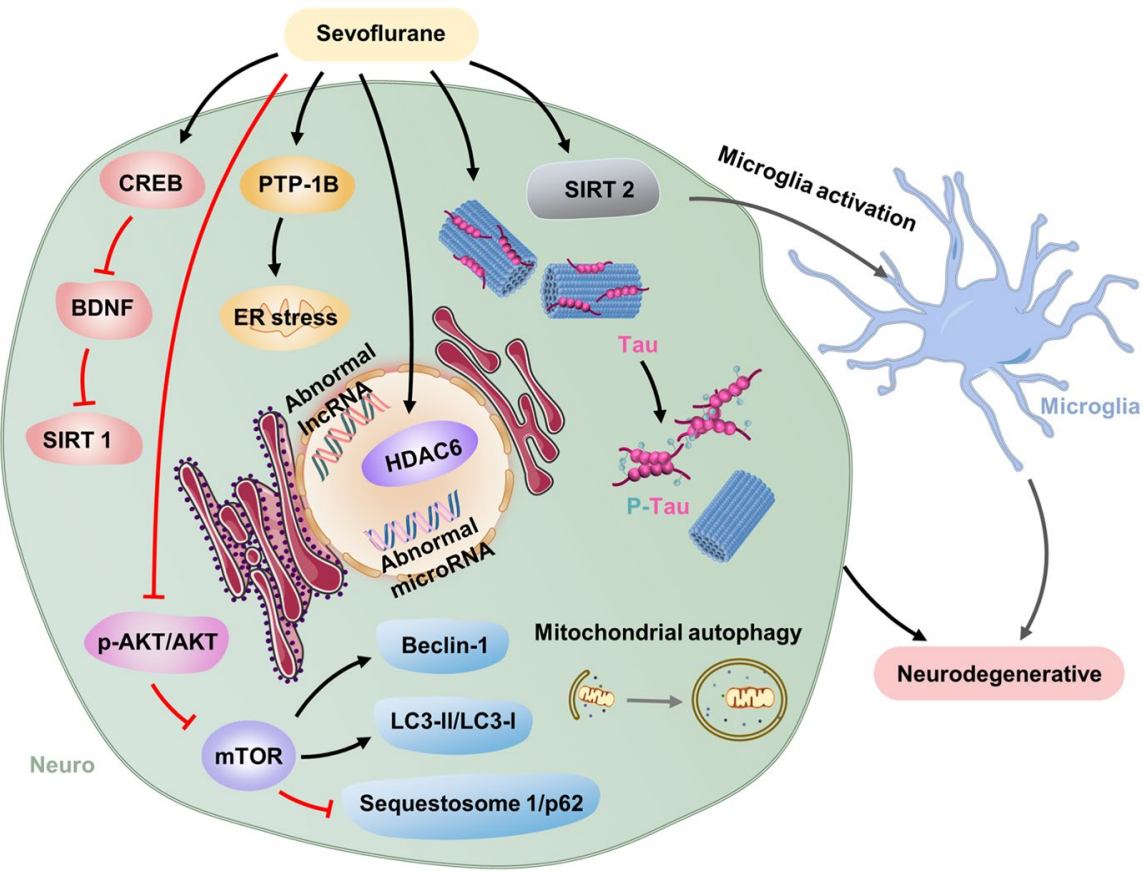

ezrin leads to astrocytic and neuronal dysfunction, which induces deficits in social behaviors of developing mice (Zhou et al., 2019). Imbalance of calcium homeostasis is an important mechanism of neurotoxicity induced by sevoflurane anesthesia, which is related to mitochondrial dysfunction and astrocytic and neuronal dysfunction. Maintaining intracellular calcium homeostasis may be an effective intervention for sevoflurane-induced developmental neurotoxicity.

Metabolic disorders contribute to sevoflurane-induced neural cell damage

Sevoflurane exposure in the developing brain decreases the intermediates in the glucose metabolic pathway, including lactate, succinic acid levels significantly decrease, and the total creatine pool, including high-energy phosphocreatine and creatine are significantly reduced (Liu et al., 2015a). Total creatine pool depletion could increase the vulnerability of cellular to insufficiency of ATP synthesis, leading to cellular dysfunction (Liu et al., 2015a; Tsuji et al., 1995). In the neonatal brain, altered amino acid metabolism may also play a key role in sevoflurane-induced neurotoxicity. Prolonged and high concentration exposure to sevoflurane reduces levels of glutamine, glutamic acid, aspartic acid, and proline significantly. These amino acids are involved in the peptides, fatty acids, and synthesis of proteins, and reduction of their levels (Liu et al., 2015a) suggests neural cell damage and inhibition of neuronal growth in the developing brain. Additionally, prolonged sevoflurane anesthesia significantly reduces the levels of cadherin 1 (CDH1) in postnatal day 7 mice, which results in glucose metabolism switched from the pentose phosphate pathway to neuronal glycolysis. This conversion leads to an imbalance between the production of reactive oxygen species and decreased glutathione levels in the developing brain. The brain is more susceptible to oxidative stress, leading to cell damage. (Liu et al., 2019a). Sevoflurane-induced neuronal damage is also related to changes in lipid composition and content. Specific lipid changes can provide insight into the molecular mechanism of anesthesia-induced neurotoxicity, and may be a sensitive biomarker for anesthesia-induced neuronal damage, which can be used for early detection (Liu et al., 2015b).

Iron metabolism, folic acid metabolism, and other imbalances also can lead to nerve damage. The balance of brain iron metabolism is vital to the development of brain tissue. Especially in fetuses or infants, iron deficiency affects myelination and nerve tissue development, which plays a key role in cognitive function. Exposure to sevoflurane during pregnancy 
will reduce the expression of light chain ferritin, heavy chain ferritin, myelin basic protein tight junction protein $\mathrm{ZO}-1$, claudin-5, occludin, and ferroportin-1 and increase the hippocampus and ferroportin-1 of offspring mice. Transferrin receptor 1 in the cortex, causing iron deficiency in the offspring's brain and impaired myelin development (Zuo et al., 2021, 2020). Ferroptosis may also be involved in cognitive impairment caused by sevoflurane in the developing brain, which may be related to activation of N-methyl-D-aspartate receptor (NMDAR)RASD1(Ras-related dexamethasone-induced 1) signaling (Wu et al., 2020a). Moreover, sevoflurane also leads to disrupted folate metabolism and subsequent defects in myelination in the developing brain (Zhang et al., 2019a). Metabolism is involved in all phases of cell growth, and metabolism disorders may lead to cell damage, which contributes to sevofluraneinduced neurotoxicity. However, there are only a few studies aimed at determining the role of metabolism in anesthesia developmental neurotoxicity.

Neuroinflammation plays an important role in cognitive impairment

The primary characteristic of neuroinflammation is overexpression of proinflammatory factors from glial activation or immune cell infiltration. Neuroinflammation conventionally refers to the ability of the central and peripheral nervous system to generate innate immune responses during pathological events (Mendiola and Cardona, 2018). Mounting inflammatory responses to injury, astroglia, and microglia are considered the hallmark effector cells. Activated microglia are a predominant source of cytokines in the central nervous system and release a series of proinflammatory cytokines and chemokines, such as monocyte chemoattractant protein-1, interleukins, macrophage colony-stimulating factor, tumor necrosis factor (TNF)- $\alpha$, and macrophage inflammatory protein- $1 \alpha / \beta$. Astrocytes express receptors for interleukin (IL)-1, IL-8, IL-6, and macrophage colony-stimulating factor (Kanthasamy et al., 2019). Overexpression of these pro-inflammatory cytokines and chemokines can cause neuronal damage (Chen et al., 2018; Takahashi et al., 2008). Repeated sevoflurane exposure in neonatal mice promotes activation of microglia and release of pro-inflammatory factors and increases neuroinflammatory factor (TNF- $\alpha$,
IL-8, IL-6, and IL-1 $\beta$ ) expression levels (Shen et al., 2013; Xia et al., 2017; Yang et al., 2020b). The PI3K/ Akt/mTORpathway in the cortex and hippocampus of rats may be involved in sevoflurane-induced developmental neurotoxicity (Wang and Wang, 2019). Meanwhile, exposure of monkeys to sevoflurane during rapid brain development also promotes microglia activation, which can be detected by upregulating translocator protein (TSPO) expression (Zhang et al., 2016). Maternal exposure to sevoflurane directly influences fetal glial cells and enhances IL-6 via phospho-ERK signaling (Hirotsu et al., 2019). Neuroinflammation is involved in sevoflurane-induced developmental neurotoxicity and could be an important target for further studies of sevoflurane-induced developmental neurotoxicity.

\section{Assembly and plasticity of neural circuits}

Impaired synaptic plasticity directly leads to abnormal neural circuitry in early brain development

Impaired synaptic plasticity contributes to cognitive deficits, emotional disorders, and poor movement and flexibility. Brain plasticity refers to the ability of neural activity generated by experience, which can change the function of neural circuits, thereby changing the subsequent feelings, thoughts, and behaviors. Synaptic plasticity refers to the activitydependent modification of the synaptic transmission efficiency or strength of pre-existing synapses, and has been proposed to play a central role in the brain's ability to incorporate short-lived experiences into persistent memory traces. Synaptic plasticity also plays a key role in the early development of neural circuits, and damage to synaptic plasticity can lead to several significant neuropsychiatric disorders (Citri and Malenka, 2008). Two main types of ionotropic glutamate receptor NMDAR and $\alpha$-amino-3-hydroxy-5-methyl-4-isoxazole propionic acid receptor (AMPAR) are involved in the postsynaptic glutamatergic synapse reaction. Defective hippocampal synaptic plasticity is closely related to defective hippocampal-dependent memory. Inhibition of expression of NMDAR and NMDAR subunit NR1 leads to defective LTP and spatial learning. Overexpression of NMDAR subunit NR2B in mice enhances LTP and enhances spatial learning (Citri 
and Malenka, 2008). Thus, synaptic plasticity plays a key role in hippocampal-dependent learning.

During critical periods of early postnatal development, brief sevoflurane exposure can induce subtle changes in synaptic plasticity and spine density (Qiu et al., 2016). Neonatal sevoflurane exposure leads to cyclin-dependent kinase 5 (CDK5) activation by increasing p25 expression (Liu et al., 2017b) and activates the CDK5/collapsin response mediator protein-2 (CRMP2) pathway and GSK-3 $\beta /$ CRMP2 pathways (Liao et al., 2021) in the hippocampus of neonatal rats. Exposure also suppresses cortical and hippocampal dendritic branching and reduces dendritic branch length as well as the density of dendritic spines in pyramidal neurons (Liao et al., 2021).

Additionally, exposure to sevoflurane reduces the expression of postsynaptic density 95 protein (PSD95), synaptophysin, and drebrin in the hippocampus, which induces impaired memory in rats and inhibits LTP in hippocampal slices (Liao et al., 2021). The interaction of nectin- 1 and L-afadin participates in the remodeling and formation of rat brain dendritic spines. Neonatal sevoflurane inhalation could activate corticotropin-releasing hormone (CRH)/ corticotropin-releasing hormone receptor (CRHR)1 signaling to decrease nectin-1 expression levels in the hippocampus, which leads to synaptic spine loss as well as learning and memory deficits in adult mice (Li et al., 2019b). Meanwhile, sevoflurane shortens the branch length of neurons and decreases the number of branches and branch nodes (Zhang et al., 2021). Multiple sevoflurane exposures reduce synaptic function in the developing cortex (Zhou et al., 2019) and enhance HDAC6 expression and activity in the hippocampus of the developing brain, which can decrease synaptophysin and PSD-95 expression and cause synaptic ultrastructural damage and cognitive deficits in adulthood (Li et al., 2019a; Tao et al., 2016). Sevoflurane also promotes the degradation of PSD-95 protein by acting on the ubiquitinated proteasome pathway, thereby reducing PSD-95 levels (Lu et al., 2017; Wang et al., 2013a), and the expression levels of PSD-95 and synaptophysin decreased in fetus and offspring mice after pregnant mice received sevoflurane anesthesia (Zheng et al., 2013). Loss of PSD-95 releases AMPA receptors from the postsynaptic membrane, allowing subsequent removal of PSD-95 from synaptic sites by endocytosis, which leads to young mice cognitive impairment (Beique et al., 2006).

Prolonged exposure to sevoflurane reduces synaptogenesis and dendritic spine formation (Yu et al., 2020b), and results in increased expression of synaptic vesicle-related proteins, decreased apical dendritic spine density, and damage to the ultrastructure of hippocampal synapses (Xiao et al., 2015), leading to cognitive functional impairments in juvenile rats. Neonatal sevoflurane exposure inhibits SIRT1 protein levels through downregulating BDNF via methylcytosine guanine phosphate-binding protein 2 (MeCP2) and CREB (Tang et al., 2020); abnormal reduction of SIRT 1 protein is associated with impaired synaptic plasticity. Sevoflurane exposure regulates the transport of NMDAR subunit NR2B and the morphology of dendritic spines (Tang et al., 2018), decreases NOVA2 expression in the developing mice cerebral cortex, inhibits Netrin-1/DCC activity in the fetal brain, interferes with the axon growth and the guidance of commissural interneurons, and reduces the migration of interneuron progenitor cells in the spinal cord (Chai et al., 2020). Multiple exposures of the developing brain to sevoflurane inhibit activation of the tyrosine kinase receptor (TrkB) signaling pathway through the imbalance of the tPA/PAI-1 fibrinolytic system and the reduction of synaptic plasticity and inhibit the cleavage of proBDNF to mBDNF (Dong et al., 2020b). Synaptic plasticity plays an important role in sevoflurane-induced neurotoxicity during development, which directly induces abnormal neural circuitry. Therefore, it is important to prevent or treat sevoflurane-associated impairment of synaptic plasticity (Fig. 4).

Abnormal myelin development results in impaired nerve conduction

Abnormal development of myelin structures in the white matter of the brain can result in impaired nerve conduction, mainly manifested as dyskinesia and postural abnormalities, but also accompanied by sensory, cognitive, and behavioral disorders. Myelination is the process by which oligodendrocytes of the CNS or Schwann cells of the peripheral nervous system wrap axons (Choi et al., 2019; Nave and Werner, 2014), which helps provide the foundation for brain connectivity and plays an important role in cognitive development and brain 


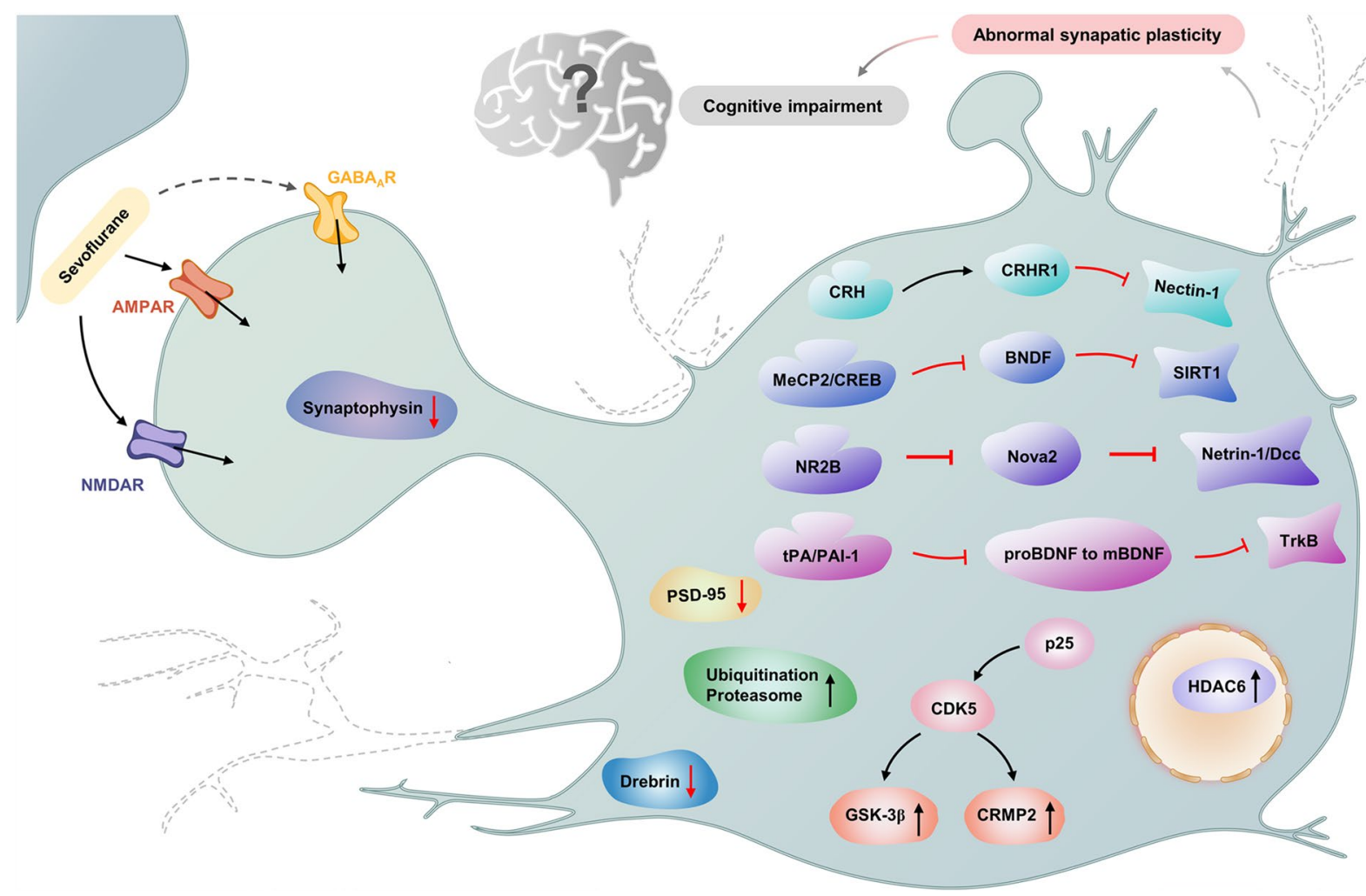

Fig. 4 Sevoflurane regulated signaling pathways through AMPAR and NMDAR, which result in abnormal synaptic plasticity. HDAC6, P25/CDK5/GSK-3 $\beta$ axis, P25/CDK5/ CRMP2 axis, and ubiquitination-proteasome involved in these signaling pathways, which activation could decrease PSD-95, drebrin, and synaptophysin levels, resulting in synaptic plas-

plasticity (Deoni et al., 2018). In the CNS, myelination is stimulated by axonal activity and astrocytes, whereas microglia/macrophages involved in myelin clearance. Myelin sheath accelerates axon signal conduction and serves an important role in preserving the healthy connectivity and functions of nervous system (Nave and Werner, 2014). Oligodendrocytes/oligodendrocyte progenitor cells are crucial for effective myelination in the CNS (Thomason et al., 2020). Oligodendrocytes (OLs) are the myelinating cells during development and throughout adulthood in the CNS. In the process of myelination, decreased expression of OL-related genes and myelin-related genes can lead to myelin dysplasia, neuronal degeneration, and nerve injury (Ogawa et al., 2018); and OL apoptosis also leads to demyelination and neurodegeneration (Dulamea, 2017). ticity decreased and cognitive impairment. Sevoflurane could decrease synaptic plasticity through CRH/CRHR1/Nectin1axis, MeCP2/CREB/BNDF/SIRT1 axis, NR2B/Nova2/ Netrin-1/DCC axis, and tPA/PAI-1/BNDF/TrkB axis, which induce synaptic plasticity decreased and cognitive impairment also. The dotted line bids for missing synapses

Sevoflurane-exposed developing nonhuman primate brains display significant apoptosis in gray and white matter, with OL apoptosis heavily concentrated in white matter zones (Ikonomidou et al., 2019; Rosado-Mendez et al., 2019), which leads to myelin dysplasia in the CNS and affects cognitive function. Exposure to high concentrations (4.9\%) of sevoflurane in the early postnatal period for $2 \mathrm{~h}$ may have a harmful effect on the OL maturation and myelination of white matter in the brain development of rats (Wu et al., 2020b). Repeated sevoflurane anesthesia in rhesus macaques and mice leads to disrupted folate metabolism and subsequent defects in myelination in the developing brain via decreased expression of myelination-development-related genes (Zhang et al., 2019a). In the CNS, iron deficiency affects myelinogenesis, especially in the fetus or infant (Ward et al., 
2014). During pregnancy, sevoflurane anesthesia in mice may inhibit myelinization in offspring via iron deficiency, leading to decreased growth of OLs, destroyed myelin integrity, reduced g-ratio of myelin sheath, and suppressed myelinization (Zuo et al., 2020). OL apoptosis, iron deficiency, and folate deficiency may be possible mechanisms of the abnormal myelin development in the developing brain caused by sevoflurane, and inhibition of OL apoptosis and supplementation of iron and folic acid may be preventive measures. More studies are needed.

miRNAs and lncRNAs are associated with sevoflurane-induced neurotoxicity

Non-coding RNAs (ncRNAs) and their related regulatory networks are increasingly involved in mediating complex neurobiological functions. miRNAs and lncRNAs have been reported to play significant roles in neural development (Rodrigues et al., 2020; Shu et al., 2019). In the mouse hippocampus, sevoflurane induces abnormal expression of 148 mRNAs and 301 lncRNAs on PD7 (Jiang et al., 2021a). These dysregulated lncRNAs/mRNAs can form a wide range of molecular networks and may participate in various functional neurological pathways in the hippocampus, leading to acute apoptosis and impaired long-term memory. Neonatal sevoflurane anesthesia can upregulate caspase 3 and Bax, decrease the levels of Bcl-2, BDNF, and NGF, and reduce the density of the hippocampal nerve through upregulation of IncRNA, resulting in ultrastructural changes of neuron cells and neuronal apoptosis (Hu et al., 2019). LncRNA Rik-203 (Zhang et al., 2019b), the PEG13/ miR-128-3p/SOX13 axis (Jiang et al., 2020), the miR410-3p/atrophin-1 pathway (Zhang et al., 2020b), the Gm15621/Mir-133A/SOX4 axis (Zhao and Ai, 2020), and the hsa-miR-302e/OXR1 axis (Yang et al., 2018) are all involved in the neurotoxicity caused by repeated sevoflurane exposure in the developing brain. Sevoflurane induces increased methylation of the presynaptic marker synaptophysin at the mRNA level and enrichment by m6A (Zhang et al., 2021), which decreases the expression of synaptophysin and leads to fine motor and cognitive impairment in young mice (Zhang et al., 2021). The damage of miRNA and lncRNA circuits causes potentially reversible and irreversible changes in brain function and structure. The role of miRNAs and lncRNAs in the anesthetic neurotoxicity of the developing brain deserves more attention.

\section{Tau phosphorylation is an important and new mechanism of sevoflurane-induced developmental neurotoxicity}

Tau phosphorylation gives us a new perspective on sevoflurane-induced cognitive dysfunction in neonatal mice. Tau protein, as a microtubule-associated protein, first reported in 1975 (Weingarten et al., 1975). Tau predominantly functions to promote assembly and stability of microtubules, which are depressed by excessive phosphorylation of tau (Pirscoveanu et al., 2017). Excessive tau phosphorylation promotes formation of insoluble tau aggregates. Once the aggregate is formed, it can escape the original cell, contact the connected cell, enter the cell, and induce further aggregation through the template conformational change (Holmes and Diamond, 2014). These conformational changes are thought to mediate neuronal dysfunction and cognitive impairment in Alzheimer's disease and other tauopathies. Tauopathy, including tau phosphorylation, is a hallmark of Alzheimer's disease neuropathogenesis (Bejanin et al., 2017). Tau phosphorylation can lead to cognitive dysfunction in mice (Faraco et al., 2019). Multiple, but not single, postnatal 6-day mice exposure to $3 \%$ sevoflurane $2 \mathrm{~h}$ daily induced phosphorylation of tau via GSK-3 $\beta$ activation, which increased the level of IL-6 and decreased the level of PSD-95 in the hippocampus, leading to cognitive impairment (Tao et al., 2014). These effects of sevoflurane did not occur in tau KO mice, suggesting the contribution of tau in sevoflurane-induced neuroinflammation and synaptic deficits in mice. Sevoflurane-induced tau phosphorylation may also explain the age-dependent changes in anesthesia neurotoxicity in mice. Neonatal mice have lower levels of mitochondrial function, which causes lower ATP and higher NUAK1 amounts in the brain. Increased NUAK1 could induce tau phosphorylation at serine 356 , blocking tau degradation (Lasagna-Reeves et al., 2016) and resulting in increased accumulation of tau (Yu et al., 2020a) in the brain tissues of neonatal mice compared to adult mice. Thus, neonatal mice are more vulnerable to the development of tau phosphorylation following sevoflurane anesthesia compared to adult mice. 
$\alpha-2$ adrenergic receptor agonists dexmedetomidine can attenuate isoflurane-induced neurocognitive impairment in neonatal rats (Sanders et al., 2009). Recently, we found that $\alpha-2$ adrenergic receptor agonists, dexmedetomidine and clonidine, can alleviate tau phosphorylation and cognitive dysfunction in neonatal mice induced by sevoflurane (Sun et al., 2021). Importantly, these effects can be inhibited by $\alpha-2$ adrenergic receptor antagonist yohimbine (Sun et al., 2021). These data suggest that $\alpha-2$ adrenergic receptor is involved in sevoflurane-induced tau phosphorylation. However, the underlying mechanism by which the $\alpha-2$ adrenergic receptor contributes to tau phosphorylation remains unknown at present and deserves further study. Another recent study demonstrated that sevoflurane can induce tau phosphorylation and extracellular vesicle-associated tau trafficking from neurons to microglia, leading to generation of IL-6 and cognitive dysfunction (Dong et al., 2021). These findings suggest that we may use sevoflurane as a research tool to investigate tau trafficking and other tauopathies in vitro and in mice. Tau phosphorylation has long been shown to occur in the brain tissues of Alzheimer's disease patients, Alzheimer's disease transgenic mice, and aged mice. However, these new findings show that tau phosphorylation may also contribute to neurotoxicity in young brains. Future studies to further reveal the role of tau in anesthesia developmental neurotoxicity are certainly warranted (Fig. 5).

\section{Neuroendocrine contribution to neurotoxicity induced by sevoflurane}

The neuroendocrine system may be involved in sevoflurane-induced neurotoxicity through $\gamma$-aminobutyric acid (GABA) receptors. As an important part of the neuroendocrine system, the limbic-hypothalamo-pituitary-adrenal (LHPA) axis plays an important role in the development of the nervous system and also has an important impact on learning, memory, and cognition (Hankin et al., 2015). $\mathrm{Cl}^{-}$is the main charge carrier through $\mathrm{GABA}_{\mathrm{A}} \mathrm{R}$ channels (Salmon et al., 2020), which is mainly regulated by $\mathrm{Cl}^{-}$transporters $\mathrm{Na}+-\mathrm{K}+-2 \mathrm{Cl}-(\mathrm{NKCC} 1)$ and $\mathrm{K}+-2 \mathrm{Cl}-(\mathrm{KCC} 2)$.

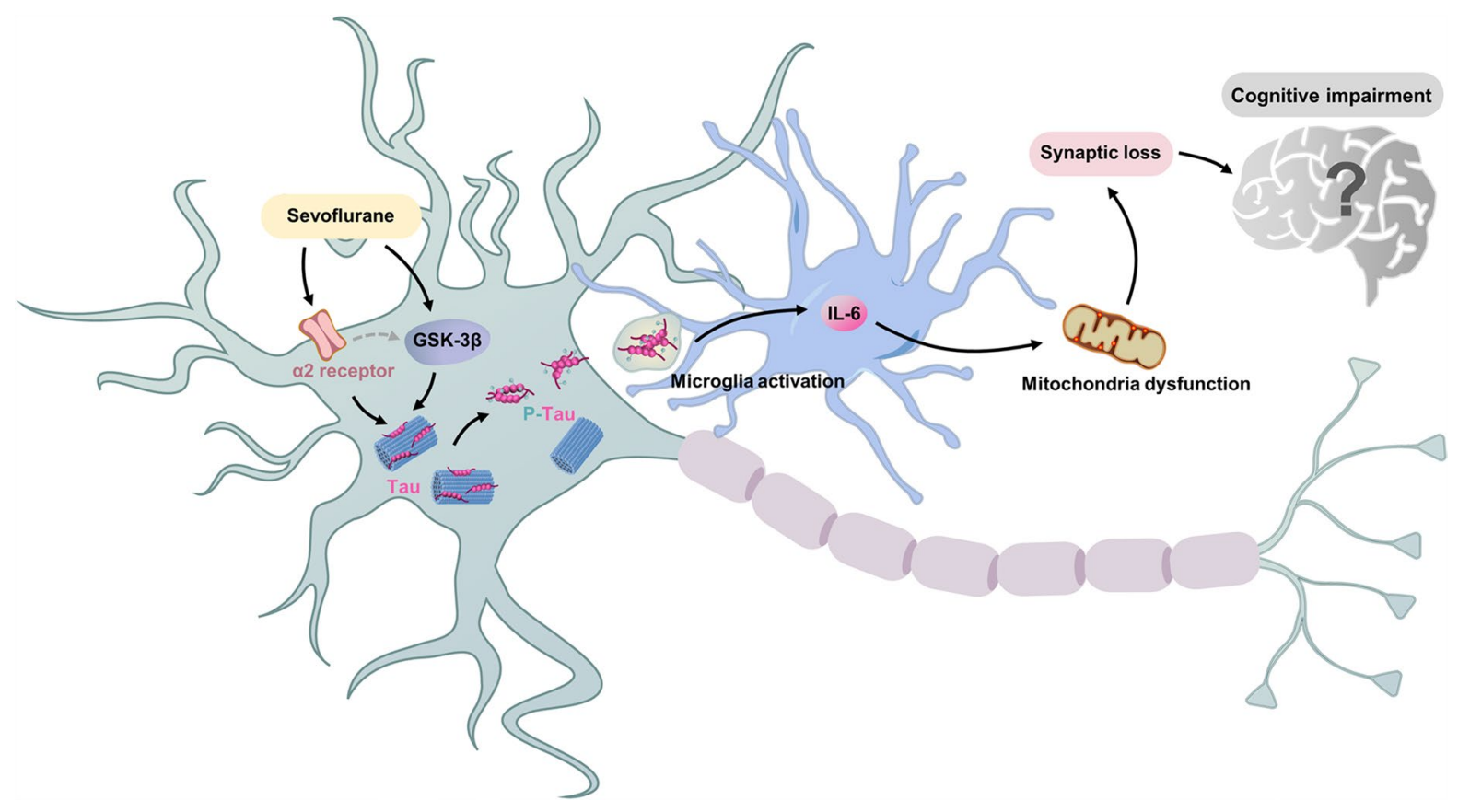

Fig. 5 Sevoflurane increased Tau phosphorylation in the young mice through GSK-3 $\beta$ and/or $\alpha-2$ adrenergic receptor. Tau phosphorylation could promote extracellular vesicleassociated tau trafficking from neurons to microglia, which led to microglia activation and promoted generation of IL-6.The elevation of IL-6 amounts led to mitochondria dysfunction and synaptic loss, which induced cognitive impairment 
Interfering with the balance of $\mathrm{NKCC} 1 / \mathrm{KCC} 2$ may cause excessive excitement of the circuit and lead to neurodevelopmental disorders. NKCC1 and KCC2 are sensitive to neuronal damage, and the imbalance of their expression is thought to cause a variety of neuropathic diseases (Cabrera et al., 2019). Sevoflurane exposure enhances $\mathrm{GABA}_{\mathrm{A}} \mathrm{R}$ activity in immature neurons, which induces increasing $\mathrm{GABA}_{\mathrm{A}} \mathrm{R}$-mediated depolarization and corticosteroid levels and electroencephalography-detectable seizures (Xu et al., 2015). 17b-estradiol contributes to the activity of $\mathrm{GABA}_{\mathrm{A}} \mathrm{R}$ ( $\mathrm{Li}$ et al., 2020), which can reduce the expression of $\mathrm{KCC} 2$, increase the ratio of NKCC1/KCC2 (Chastain-Potts et al., 2020; Martynyuk et al., 2020), and induce neurodevelopmental impairments. Sevoflurane induces cognitive impairment through increasing the ratio of NKCC1/ KCC2 by activating $\mathrm{GAB}_{\mathrm{A}} \mathrm{R}$ and increasing the level of corticosteroid, especially 17b-estradiol. These results may illustrate another mechanism by which sevoflurane causes developmental anesthesia neurotoxicity.

\section{Our perspective}

Although there are many mechanisms by which sevoflurane induces developmental neurotoxicity, we believe that tau phosphorylation deserves more attention in the future. There are many new techniques and methods in other fields, such as single-cell omics (Wu et al., 2021), proteomics (Qiao and Wang, 2019), metabolomics (Zhang et al., 2020a), nanotechnology (Liang et al., 2016), and ultrasound/photoacoustic imaging ( $\mathrm{Li}$ et al., 2021). These advanced technologies should be applied in future studies to paint a dynamic, multi-level, multi-dimensional picture of the molecular mechanisms of sevoflurane-induced developmental neurotoxicity. The outcomes of these studies could lead to better outcomes in caring for children.

\section{Conclusion}

The developing brain may be uniquely vulnerable to anesthesia, pending further investigation. The mechanisms of sevoflurane-induced developmental neurotoxicity could include neural cell death, neural cell damage, impaired assembly and plasticity of neural circuits, tau phosphorylation, and neuroendocrine system abnormalities, among others. More research is needed to further reveal the underlying mechanisms by which sevoflurane and other anesthetics can induce developmental neurotoxicity.

Funding This work was supported by the National Natural Science Foundation of China (NSFC: No. 81901110 to Mingyang Sun, No. 82071217 to Jiaqiang Zhang).

Data availability Data sharing not applicable to this article as no datasets were generated or analyzed during the current study.

Code availability Not applicable.

Declarations

Ethics approval Not applicable.

Consent to participate Written informed consents were collected from all participants before enrollment.

Consent for publication All contributing authors agree to the publication of this article.

Conflict of interest The authors declare no competing interests.

Open Access This article is licensed under a Creative Commons Attribution 4.0 International License, which permits use, sharing, adaptation, distribution and reproduction in any medium or format, as long as you give appropriate credit to the original author(s) and the source, provide a link to the Creative Commons licence, and indicate if changes were made. The images or other third party material in this article are included in the article's Creative Commons licence, unless indicated otherwise in a credit line to the material. If material is not included in the article's Creative Commons licence and your intended use is not permitted by statutory regulation or exceeds the permitted use, you will need to obtain permission directly from the copyright holder. To view a copy of this licence, visit http://creativecommons.org/licenses/by/4.0/.

\section{References}

U.S. Food and Drug Administration: Drug safety communication: FDA review results in new warnings about using general anesthetics and sedation drugs in young children and pregnant women. 2016. Available at:https:// www.fda.gov/drugs/drug-safety-and-availability/ 
fda-drug-safety-communication-fda-review-results-newwarnings-about-using-general-anesthetics-and.issued on December 14, 2016

Barrett RM, Malvaez M, Kramar E, Matheos DP, Arrizon A, Cabrera SM, Lynch G, Greene RW, Wood MA. Hippocampal focal knockout of CBP affects specific histone modifications, long-term potentiation, and long-term memory. Neuropsychopharmacology. 2011;36:1545-56.

Beique JC, Lin DT, Kang MG, Aizawa H, Takamiya K, Huganir RL. Synapse-specific regulation of AMPA receptor function by PSD-95. Proc Natl Acad Sci U S A. 2006;103:19535-40.

Bejanin A, Schonhaut DR, La Joie R, Kramer JH, Baker SL, Sosa N, Ayakta N, Cantwell A, Janabi M, Lauriola M, et al. Tau pathology and neurodegeneration contribute to cognitive impairment in Alzheimer's disease. Brain. 2017;140:3286-300.

Bi C, Cai Q, Shan Y, Yang F, Sun S, Wu X, Liu H. Sevoflurane induces neurotoxicity in the developing rat hippocampus by upregulating connexin 43 via the JNK/c-Jun/AP-1 pathway. Biomed Pharmacother. 2018;108:1469-76.

Budini M, Buratti E, Morselli E, Criollo A. Autophagy and its impact on neurodegenerative diseases: new roles for TDP-43 and C9orf72. Front Mol Neurosci. 2017;10:170.

Burks SM, Bowyer JF, Walters JL, Talpos JC. Regions of the basal ganglia and primary olfactory system are most sensitive to neurodegeneration after extended sevoflurane anesthesia in the perinatal rat. Neurotoxicol Teratol. 2020;80:106890.

Cabrera OH, Tesic V, Tat QL, Chastain S, Quillinan N, Jevtovic-Todorovic V. Sevoflurane-induced dysregulation of cation-chloride cotransporters NKCC1 and KCC2 in Neonatal Mouse Brain. Mol Neurobiol. 2019;57:1-10.

Calvo-Rodriguez M, Bacskai BJ. Mitochondria and calcium in Alzheimer's disease: from cell signaling to neuronal cell death. Trends Neurosci. 2021;44:136-51.

Chai D, Yan J, Li C, Sun Y, Jiang H. Sevoflurane inhibits neuronal migration and axon growth in the developing mouse cerebral cortex. Aging (albany NY). 2020;12:6436-55.

Chastain-Potts SE, Tesic V, Tat QL, Cabrera OH, Quillinan N, Jevtovic-Todorovic V. Sevoflurane exposure results in sex-specific transgenerational upregulation of target IEGs in the subiculum. Mol Neurobiol. 2020;57:11-22.

Chen J, Zhang DM, Feng X, Wang J, Qin YY, Zhang T, Huang Q, Sheng R, Chen Z, Li M, et al. TIGAR inhibits ischemia/reperfusion-induced inflammatory response of astrocytes. Neuropharmacology. 2018;131:377-88.

Chen Q, Chu W, Sheng R, Song S, Yang J, Ji F, Jin X. Maternal anesthesia with sevoflurane during the mid-gestation induces social interaction deficits in offspring C57BL/6 mice. Biochem Biophys Res Commun. 2021;553:65-71.

Chen X, Zhou X, Lu D, Yang X, Zhou Z, Chen X, Chen Y, He W, Feng X. Aberrantly expressed long noncoding RNAs are involved in sevoflurane-induced developing hippocampal neuronal apoptosis: a microarray related study. Metab Brain Dis. 2016;31:1031-40.

Chen Y, Li S, Zhong X, Kang Z, Chen R. PDE-7 Inhibitor BRL-50481 reduces neurodegeneration and long-term memory deficits in mice following devoflurane exposure. ACS Chem Neurosci. 2020;11:1353-8.
Choi EH, Blasiak A, Lee J, Yang IH. Modulation of neural activity for myelination in the central nervous system. Front Neurosci. 2019;13:952.

Citri A, Malenka RC. Synaptic plasticity: multiple forms, functions, and mechanisms. Neuropsychopharmacology. 2008;33:18-41.

Dai CL, Li H, Hu X, Zhang J, Liu F, Iqbal K, Gong CX. Neonatal exposure to anesthesia leads to cognitive deficits in old age: prevention with intranasal administration of insulin in mice. Neurotox Res. 2020;38:299-311.

Danese A, Patergnani S, Bonora M, Wieckowski MR, Previati M, Giorgi C, Pinton P. Calcium regulates cell death in cancer: roles of the mitochondria and mitochondria-associated membranes (MAMs). Biochim Biophys Acta Bioenerg. 2017;1858:615-27.

Davidson AJ, Disma N, de Graaff JC, Withington DE, Dorris L, Bell G, Stargatt R, Bellinger DC, Schuster T, Arnup $\mathrm{SJ}$, et al. Neurodevelopmental outcome at 2 years of age after general anaesthesia and awake-regional anaesthesia in infancy (GAS): an international multicentre, randomised controlled trial. Lancet. 2016;387:239-50.

Deoni S, Dean D 3rd, Joelson S, O’Regan J, Schneider N. Early nutrition influences developmental myelination and cognition in infants and young children. Neuroimage. 2018;178:649-59.

Dikranian K, Ishimaru MJ, Tenkova T, Labruyere J, Qin YQ, Ikonomidou C, Olney JW. Apoptosis in the in vivo mammalian forebrain. Neurobiol Dis. 2001;8:359-79.

DiMaggio C, Sun LS, Li, G. Early childhood exposure to anesthesia and risk of developmental and behavioral disorders in a sibling birth cohort. Anesth Analg. 2011;113:1143-1151.

Dong Y, Hong W, Tang Z, Gao Y, Wu X, Liu H. Dexmedetomidine attenuates neurotoxicity in developing rats induced by sevoflurane through upregulating BDNF-TrkB-CREB and downregulating ProBDNF-P75NRT-RhoA signaling pathway. Mediators Inflamm. 2020a;2020:5458061.

Dong Y, Hong W, Tang Z, Gao Y, Wu X, Liu H. Sevoflurane leads to learning and memory dysfunction via breaking the balance of tPA/PAI-1. Neurochem Int. 2020;139:104789.

Dong Y, Liang F, Huang L, Fang F, Yang G, Tanzi RE, Zhang Y, Quan Q, Xie Z. The anesthetic sevoflurane induces tau trafficking from neurons to microglia. Commun Biol. 2021;4:560.

Dulamea AO. Role of oligodendrocyte dysfunction in demyelination, remyelination and neurodegeneration in multiple sclerosis. Adv Exp Med Biol. 2017;958:91-127.

Faraco G, Hochrainer K, Segarra SG, Schaeffer S, Santisteban MM, Menon A, Jiang H, Holtzman DM, Anrather J, Iadecola C. Dietary salt promotes cognitive impairment through tau phosphorylation. Nature. 2019;574:686-90.

Green DR, Llambi F. Cell death signaling. Cold Spring Harb Perspect Biol. 2015;7(12).

Hankin BL, Badanes LS, Smolen A, Young JF. Cortisol reactivity to stress among youth: stability over time and genetic variants for stress sensitivity. J Abnorm Psychol. 2015;124:54-67.

Heras-Sandoval D, Perez-Rojas JM, Hernandez-Damian J, Pedraza-Chaverri J. The role of PI3K/AKT/mTOR pathway in the modulation of autophagy and the clearance 
of protein aggregates in neurodegeneration. Cell Signal. 2014;26:2694-701.

Hetz C, Saxena S. ER stress and the unfolded protein response in neurodegeneration. Nat Rev Neurol. 2017;13:477-91.

Hirotsu A, Iwata Y, Tatsumi K, Miyai Y, Matsuyama T, Tanaka T. Maternal exposure to volatile anesthetics induces IL-6 in fetal brains and affects neuronal development. Eur J Pharmacol. 2019;863:172682.

Holmes BB, Diamond MI. Prion-like properties of Tau protein: the importance of extracellular Tau as a therapeutic target. J Biol Chem. 2014;289:19855-61.

$\mathrm{Hu} \mathrm{X}, \mathrm{Hu} \mathrm{X}$, Huang G. LncRNA MALAT1 is involved in sevoflurane-induced neurotoxicity in developing rats. J Cell Biochem. 2019;120:18209-18.

Huang, Y., Chen, Y., Kang, Z., and Li, S. (2021). Inhibiting PDE7A enhances the protective effects of neural stem cells on neurodegeneration and memory deficits in sevoflurane-exposed mice. eNeuro 8(4).

Ikonomidou C, Kirvassilis G, Swiney BS, Wang SH, Huffman JN, Williams SL, Masuoka K, Capuano S 3rd, Brunner $\mathrm{KR}$, Crosno K, et al. Mild hypothermia ameliorates anesthesia toxicity in the neonatal macaque brain. Neurobiol Dis. 2019;130:104489.

Jiang C, Arzua T, Yan Y, Bai X. Expression signature of lncRNAs and mRNAs in sevoflurane-induced mouse brain injury: implication of involvement of wide molecular networks and pathways. Int J Mol Sci. 2021a;22:1389.

Jiang C, Arzua T, Yan Y, Bai X. Expression signature of lncRNAs and mRNAs in sevoflurane-induced mouse brain injury: implication of involvement of wide molecular networks and pathways. Int J Mol Sci. 2021b;22(3).

Jiang Y, Wang Y, Sun Y, Jiang H. Long non-coding RNA Peg13 attenuates the sevoflurane toxicity against neural stem cells by sponging microRNA-128-3p to preserve Sox 13 expression. PLoS One. 2020;15:e0243644.

Jin Y, Li H, Xie G, Chen S, Wu S, Fang X. Sevoflurane combined with ATP activates caspase-1 and triggers caspase1-dependent pyroptosis in murine $\mathrm{J} 774$ macrophages. Inflammation. 2013;36:330-6.

Kanthasamy A, Jin H, Charli A, Vellareddy A, Kanthasamy A. Environmental neurotoxicant-induced dopaminergic neurodegeneration: a potential link to impaired neuroinflammatory mechanisms. Pharmacol Ther. 2019;197:61-82.

Klionsky DJ, Abdelmohsen K, Abe A, Abedin MJ, Abeliovich $\mathrm{H}$, Acevedo Arozena A, Adams H, Adams CM, Adeli PDK, et al. Guidelines for the use and interpretation of assays for monitoring autophagy (3rd edition). Autophagy. 2016;12:1-222.

Lasagna-Reeves CA, de Haro M, Hao S, Park J, Rousseaux MW, Al-Ramahi I, Jafar-Nejad P, Vilanova-Velez L, See L, De Maio A, et al. Reduction of Nuak1 decreases tau and reverses phenotypes in a tauopathy mouse model. Neuron. 2016;92:407-18.

Lee YY, Moujalled D, Doerflinger M, Gangoda L, Weston R, Rahimi A, de Alboran I, Herold M, Bouillet P, Xu $\mathrm{Q}$, et al. CREB-binding protein (CBP) regulates betaadrenoceptor (beta-AR)-mediated apoptosis. Cell Death Differ. 2013;20:941-52.

Li G, Du J, Wang L, Shi X. Developmental neurotoxicity in the context of multiple sevoflurane exposures: potential role of histone deacetylase 6. Neurotoxicol Teratol. 2019;74:106813.

Li H, Wu Z, Zhang J, Sun X, Duan F, Yao J, Sun M, Zhang J, Nie L. Instant ultrasound-evoked precise nanobubble explosion and deep photodynamic therapy for tumors guided by molecular imaging. ACS Appl Mater Interfaces. 2021;13:21097-107.

Li N, Xu N, Lin Y, Lei L, Ju LS, Morey TE, Gravenstein N, Zhang J, Martynyuk AE. Roles of testosterone and estradiol in mediation of acute neuroendocrine and electroencephalographic effects of sevoflurane during the sensitive period in rats. Front Endocrinol (Lausanne). 2020;11:545973.

Li R, Zhang LM, Sun WB. Erythropoietin rescues primary rat cortical neurons from pyroptosis and apoptosis via Erk1/2-Nrf2/Bach1 signal pathway. Brain Res Bull. 2017a;130:236-44.

Li X, Wu Z, Zhang Y, Xu Y, Han G, Zhao P. Activation of autophagy contributes to sevoflurane-induced neurotoxicity in fetal rats. Front Mol Neurosci. 2017b;10:432.

Li Y, Zhang L, Wang C, Tang X, Chen Y, Wang X, Su L, $\mathrm{Hu}$ N, Xie K, Yu Y, et al. Sevoflurane-induced learning deficits and spine loss via nectin-1/corticotrophinreleasing hormone receptor type 1 signaling. Brain Res. 2019b;1710:188-98.

Liang F, Zhang Y, Hong W, Dong Y, Xie Z, Quan Q. Direct tracking of amyloid and tau dynamics in neuroblastoma cells using nanoplasmonic fiber tip probes. Nano Lett. 2016;16:3989-94.

Liao Z, Huang Z, Li J, Li H, Miao L, Liu Y, Zhang J, Xu Y, Li Y. Regulation of CRMP2 by Cdk5 and GSK-3beta participates in sevoflurane-induced dendritic development abnormalities and cognitive dysfunction in developing rats. Toxicol Lett. 2021;341:68-79.

Liu B, Bai W, Ou G, Zhang J. Cdh1-mediated metabolic switch from pentose phosphate pathway to glycolysis contributes to sevoflurane-induced neuronal apoptosis in developing brain. ACS Chem Neurosci. 2019a;10:2332-44.

Liu B, Gu Y, Xiao H, Lei X, Liang W, Zhang J. Altered metabolomic profiles may be associated with sevofluraneinduced neurotoxicity in neonatal rats. Neurochem Res. 2015a;40:788-99.

Liu B, Ou G, Chen Y, Zhang J. Inhibition of protein tyrosine phosphatase 1B protects against sevoflurane-induced neurotoxicity mediated by ER stress in developing brain. Brain Res Bull. 2019b;146:28-39.

Liu B, Xia J, Chen Y, Zhang J. Sevoflurane-induced endoplasmic reticulum stress contributes to neuroapoptosis and BACE-1 expression in the developing brain: the role of eIF2alpha. Neurotox Res. 2017a;31:218-29.

Liu F, Rainosek SW, Frisch-Daiello JL, Patterson TA, Paule MG, Slikker W Jr, Wang C, Han X. Potential adverse effects of prolonged sevoflurane exposure on developing monkey brain: from abnormal lipid metabolism to neuronal damage. Toxicol Sci. 2015b;147:562-72.

Liu X, Ji J, Zhao GQ. General anesthesia affecting on developing brain: evidence from animal to clinical research. $\mathrm{J}$ Anesth. 2020;34:765-72.

Liu Y, Lin D, Liu C, Zhao Y, Shen Z, Zhang K, Cao M, Li Y. Cyclin-dependent kinase 5/collapsin response mediator protein 2 pathway may mediate sevoflurane-induced 
dendritic development abnormalities in rat cortical neurons. Neurosci Lett. 2017b;651:21-9.

Loop T, Dovi-Akue D, Frick M, Roesslein M, Egger L, Humar M, Hoetzel A, Schmidt R, Borner C, Pahl HL, et al. Volatile anesthetics induce caspase-dependent, mitochondria-mediated apoptosis in human $\mathrm{T}$ lymphocytes in vitro. Anesthesiology. 2005;102:1147-57.

Lu H, Liufu N, Dong Y, Xu G, Zhang Y, Shu L, Soriano SG, Zheng H, Yu B, Xie Z. Sevoflurane acts on ubiquitination-proteasome pathway to reduce postsynaptic density 95 protein levels in young mice. Anesthesiology. 2017; 127:961-75

Lu Y, Wu X, Dong Y, Xu Z, Zhang Y, Xie Z. Anesthetic sevoflurane causes neurotoxicity differently in neonatal naive and Alzheimer disease transgenic mice. Anesthesiology. 2010;112:1404-16

Maddox SA, Watts CS, Schafe GE. p300/CBP histone acetyltransferase activity is required for newly acquired and reactivated fear memories in the lateral amygdala. Learn Mem. 2013;20:109-19.

Marchi S, Patergnani S, Missiroli S, Morciano G, Rimessi A, Wieckowski MR, Giorgi C, Pinton P. Mitochondrial and endoplasmic reticulum calcium homeostasis and cell death. Cell Calcium. 2018;69:62-72.

Martynyuk AE, Ju LS, Morey TE, Zhang JQ. Neuroendocrine, epigenetic, and intergenerational effects of general anesthetics. World J Psychiatry. 2020;10:81-94.

Maurer U, Charvet C, Wagman AS, Dejardin E, Green DR. Glycogen synthase kinase-3 regulates mitochondrial outer membrane permeabilization and apoptosis by destabilization of MCL-1. Mol Cell. 2006;21:749-60.

McCann ME, de Graaff J. Current thinking regarding potential neurotoxicity of general anesthesia in infants. Curr Opin Urol. 2017;27:27-33.

Mendes CC, Gomes DA, Thompson M, Souto NC, Goes TS, Goes AM, Rodrigues MA, Gomez MV, Nathanson MH, Leite MF. The type III inositol 1,4,5-trisphosphate receptor preferentially transmits apoptotic $\mathrm{Ca} 2+$ signals into mitochondria. J Biol Chem. 2005;280:40892-900.

Mendiola AS, Cardona AE. The IL-1beta phenomena in neuroinflammatory diseases. J Neural Transm (vienna). 2018;125:781-95.

Nave KA, Werner HB. Myelination of the nervous system: mechanisms and functions. Annu Rev Cell Dev Biol. 2014;30:503-33.

Ogawa Y, Irisa M, Sano T, Yanagi Y, Furusawa E, Saito T, Yamanaka S, Itoh K, Sakuraba H, Oishi K. Improvement in dysmyelination by the inhibition of microglial activation in a mouse model of Sandhoff disease. NeuroReport. 2018;29:962-7.

Piao M, Wang Y, Liu N, Wang X, Chen R, Qin J, Ge P, Feng C. Sevoflurane exposure induces neuronal cell parthanatos initiated by DNA damage in the developing brain via an increase of intracellular reactive oxygen species. Front Cell Neurosci. 2020;14:583782.

Pirscoveanu DFV, Pirici I, Tudorica V, Balseanu TA, Albu VC, Bondari S, Bumbea AM, Pirscoveanu M. Tau protein in neurodegenerative diseases - a review. Rom J Morphol Embryol. 2017;58:1141-50.

Qiao T, Wang X. A new light of proteomics in cell biology and toxicology. Cell Biol Toxicol. 2019;35:289-91.
Qiu L, Zhu C, Bodogan T, Gomez-Galan M, Zhang Y, Zhou $\mathrm{K}$, Li T, Xu G, Blomgren K, Eriksson LI, et al. Acute and long-term effects of brief sevoflurane anesthesia during the early postnatal period in rats. Toxicol Sci. 2016;149:121-33.

Raper J, Alvarado MC, Murphy KL, Baxter MG. Multiple anesthetic exposure in infant monkeys alters emotional reactivity to an acute stressor. Anesthesiology. 2015;123:1084-92.

Raper J, De Biasio JC, Murphy KL, Alvarado MC, Baxter MG. Persistent alteration in behavioural reactivity to a mild social stressor in rhesus monkeys repeatedly exposed to sevoflurane in infancy. Br J Anaesth. 2018;120:761-7.

Ravikumar B, Acevedo-Arozena A, Imarisio S, Berger Z, Vacher C, O'Kane CJ, Brown SD, Rubinsztein DC. Dynein mutations impair autophagic clearance of aggregate-prone proteins. Nat Genet. 2005;37:771-6.

Rodrigues DC, Mufteev M, Weatheritt RJ, Djuric U, Ha KCH, Ross PJ, Wei W, Piekna A, Sartori MA, Byres L, et al. Shifts in ribosome engagement impact key gene sets in neurodevelopment and ubiquitination in Rett syndrome. Cell Rep. 2020;30:4179-4196-e4111.

Rosado-Mendez IM, Noguchi KK, Castaneda-Martinez L, Kirvassilis G, Wang SH, Manzella F, Swiney BS, Masuoka K, Capuano S III, Brunner KG, et al. Quantitative ultrasound and apoptotic death in the neonatal primate brain. Neurobiol Dis. 2019;127:554-62.

Salmon CK, Pribiag H, Gizowski C, Farmer WT, Cameron S, Jones EV, Mahadevan V, Bourque CW, Stellwagen D, Woodin MA, et al. Depolarizing GABA transmission restrains activity-dependent glutamatergic synapse formation in the developing hippocampal circuit. Front Cell Neurosci. 2020;14:36.

Sanders RD, Xu J, Shu Y, Januszewski A, Halder S, Fidalgo A, Sun P, Hossain M, Ma D, Maze M. Dexmedetomidine attenuates isoflurane-induced neurocognitive impairment in neonatal rats. Anesthesiology. 2009;110:1077-85.

Shen X, Dong Y, Xu Z, Wang H, Miao C, Soriano SG, Sun D, Baxter MG, Zhang Y, Xie Z. Selective anesthesia-induced neuroinflammation in developing mouse brain and cognitive impairment. Anesthesiology. 2013;118:502-15.

Shu P, Wu C, Liu W, Ruan X, Liu C, Hou L, Zeng Y, Fu H, Wang $\mathrm{M}$, Chen $\mathrm{P}$, et al. The spatiotemporal expression pattern of microRNAs in the developing mouse nervous system. J Biol Chem. 2019;294:3444-53.

Song Q, Ma YL, Song JQ, Chen Q, Xia GS, Ma JY, Feng F, Fei XJ, Wang QM. Sevoflurane induces neurotoxicity in young mice through FAS/FASL signaling. Genet Mol Res. 2015;14:18059-68.

Sun LS, Li G, Miller TL, Salorio C, Byrne MW, Bellinger DC, Ing C, Park R, Radcliffe J, Hays SR, et al. Association between a single general anesthesia exposure before age 36 months and neurocognitive outcomes in later childhood. JAMA. 2016;315:2312-20.

Sun M, Dong Y, Li M, Zhang Y, Liang F, Zhang J, Soriano SG, Xie Z. Dexmedetomidine and clonidine attenuate sevoflurane-induced tau phosphorylation and cognitive impairment in young mice via alpha-2 adrenergic receptor. Anesth Analg. 2021;132:878-89. 
Takahashi K, Funata N, Ikuta F, Sato S. Neuronal apoptosis and inflammatory responses in the central nervous system of a rabbit treated with Shiga toxin-2. J Neuroinflammation. 2008;5:11.

Tang X, Li Y, Ao J, Ding L, Liu Y, Yuan Y, Wang Z, Wang G. Role of alpha7nAChR-NMDAR in sevoflurane-induced memory deficits in the developing rat hippocampus. PLoS One. 2018;13:e0192498.

Tang X, Zhao Y, Zhou Z, Yan J, Zhou B, Chi X, Luo A, Li $\mathrm{S}$. Resveratrol mitigates sevoflurane-induced neurotoxicity by the SIRT1-dependent regulation of BDNF expression in developing mice. Oxid Med Cell Longev. 2020;2020:9018624.

Tao G, Luo Y, Xue Q, Li G, Tan Y, Xiao J, Yu B. Docosahexaenoic acid rescues synaptogenesis impairment and longterm memory deficits caused by postnatal multiple sevoflurane exposures. Biomed Res Int. 2016;2016:4062579.

Tao G, Zhang J, Zhang L, Dong Y, Yu B, Crosby G, Culley DJ, Zhang Y, Xie Z. Sevoflurane induces tau phosphorylation and glycogen synthase kinase 3 beta activation in young mice. Anesthesiology. 2014;121:510-27.

Thomason EJ, Escalante M, Osterhout DJ, Fuss B. The oligodendrocyte growth cone and its actin cytoskeleton: a fundamental element for progenitor cell migration and CNS myelination. Glia. 2020;68:1329-46.

Tsuji M, Allred E, Jensen F, Holtzman D. Phosphocreatine and ATP regulation in the hypoxic developing rat brain. Brain Res Dev Brain Res. 1995;85:192-200.

Walkden GJ, Gill H, Davies NM, Peters AE, Wright I, Pickering AE. Early childhood general anesthesia and neurodevelopmental outcomes in the Avon Longitudinal Study of Parents and Children Birth cohort. Anesthesiology. 2020;133:1007-20.

Wang N, Wang M. Dexmedetomidine suppresses sevoflurane anesthesia-induced neuroinflammation through activation of the PI3K/Akt/mTOR pathway. BMC Anesthesiol. 2019;19:134.

Wang SQ, Fang F, Xue ZG, Cang J, Zhang XG. Neonatal sevoflurane anesthesia induces long-term memory impairment and decreases hippocampal PSD-95 expression without neuronal loss. Eur Rev Med Pharmacol Sci. 2013a; 17:941-50.

Wang WY, Jia LJ, Luo Y, Zhang HH, Cai F, Mao H, Xu WC, Fang JB, Peng ZY, Ma ZW, et al. Location- and subunitspecific NMDA receptors determine the developmental sevoflurane neurotoxicity through ERK1/2 signaling. Mol Neurobiol. 2016a;53:216-30.

Wang WY, Wu XM, Jia LJ, Zhang HH, Cai F, Mao H, Xu WC, Chen L, Zhang J, Hu SF. Beta-arrestin1 and 2 differently modulate metabotropic glutamate receptor 7 signaling in rat developmental sevoflurane-induced neuronal apoptosis. Neuroscience. 2016b;313:199-212.

Wang WY, Yang R, Hu SF, Wang H, Ma ZW, Lu Y. N-stearoylL-tyrosine ameliorates sevoflurane induced neuroapoptosis via MEK/ERK1/2 MAPK signaling pathway in the developing brain. Neurosci Lett. 2013b;541:167-72.

Ward RJ, Zucca FA, Duyn JH, Crichton RR, Zecca L. The role of iron in brain ageing and neurodegenerative disorders. Lancet Neurol. 2014;13:1045-60.

Warner DO, Zaccariello MJ, Katusic SK, Schroeder DR, Hanson AC, Schulte PJ, Buenvenida SL, Gleich SJ,
Wilder RT, Sprung J, et al. Neuropsychological and behavioral outcomes after exposure of young children to procedures requiring general anesthesia: the Mayo Anesthesia Safety in Kids (MASK) Study. Anesthesiology. 2018;129:89-105.

Wei H, Wang X, Dong Y, Zhang Y, Li T, Xie Z. Sevoflurane induces cognitive impairment in young mice via autophagy. Plos One. 2019;14:e0216372.

Wei H, Xie Z. Anesthesia, calcium homeostasis and Alzheimer's disease. Curr Alzheimer Res. 2009;6:30-5.

Wei K, Chen P, Shen FY, Zhang Y, Liu YH, Wang ZR, Loepke AW, Wang YW, Deng M. Defining the vulnerability window of anesthesia-induced neuroapoptosis in developing dentate gyrus granule cells - a transgenic approach utilizing POMC-EGFP mice. Neuroscience. 2019b;415:59-69.

Weingarten MD, Lockwood AH, Hwo SY, Kirschner MW. A protein factor essential for microtubule assembly. Proc Natl Acad Sci U S A. 1975;72:1858-62.

Wertz IE, Kusam S, Lam C, Okamoto T, Sandoval W, Anderson DJ, Helgason E, Ernst JA, Eby M, Liu J, et al. Sensitivity to antitubulin chemotherapeutics is regulated by MCL1 and FBW7. Nature. 2011;471:110-4.

Wu D, Liu X, Zhang J, Li L, Wang X. Significance of singlecell and spatial transcriptomes in cell biology and toxicology. Cell Biol Toxicol. 2021;37:1-5.

Wu J, Yang JJ, Cao Y, Li H, Zhao H, Yang S, Li K. Iron overload contributes to general anaesthesia-induced neurotoxicity and cognitive deficits. J Neuroinflammation. 2020a; 17:110.

Wu Z, Xue H, Gao Q, Zhao P. Effects of early postnatal sevoflurane exposure on oligodendrocyte maturation and myelination in cerebral white matter of the rat. Biomed Pharmacother. 2020;131:110733.

Wu Z, Zhang Y, Zhang Y, Zhao P. Sirtuin 2 inhibition attenuates sevoflurane-induced learning and memory deficits in developing rats via modulating microglial activation. Cell Mol Neurobiol. 2020c;40:437-46.

Xia Y, Xu H, Jia C, Hu X, Kang Y, Yang X, Xue Q, Tao G, Yu B. Tanshinone IIA Attenuates sevoflurane neurotoxicity in neonatal mice. Anesth Analg. 2017;124:1244-52.

Xiao H, Liu B, Chen Y, Zhang J. Learning, memory and synaptic plasticity in hippocampus in rats exposed to sevoflurane. Int J Dev Neurosci. 2015;48:38-49.

Xie L, Liu Y, Hu Y, Wang B, Zhu Z, Jiang Y, Suo Y, Hu M, Gao J, Ullah R, et al. Neonatal sevoflurane exposure induces impulsive behavioral deficit through disrupting excitatory neurons in the medial prefrontal cortex in mice. Transl Psychiatry. 2020;10:202.

Xu C, Tan S, Zhang J, Seubert CN, Gravenstein N, Sumners C, Vasilopoulos T, Martynyuk AE. Anesthesia with sevoflurane in neonatal rats: developmental neuroendocrine abnormalities and alleviating effects of the corticosteroid and $\mathrm{Cl}(-)$ importer antagonists. Psychoneuroendocrinology. 2015;60:173-81.

Xu L, Shen J, Yu L, Sun J, Yan M. Autophagy is involved in sevoflurane-induced developmental neurotoxicity in the developing rat brain. Brain Res Bull. 2018;140:226-32.

Xu R, Zhu Y, Jia J, Li WX, Lu Y. RIPK1/RIPK3-Mediated necroptosis is involved in sevoflurane-induced neonatal 
neurotoxicity in the rat hippocampus. Cell Mol Neurobiol. 2021

Yang F, Zhang Y, Tang Z, Shan Y, Wu X, Liu H. Hemin treatment protects neonatal rats from sevoflurane-induced neurotoxicity via the phosphoinositide 3-kinase/Akt pathway. Life Sci. 2020;242:117151.

Yang H, Liang G, Hawkins BJ, Madesh M, Pierwola A, Wei H. Inhalational anesthetics induce cell damage by disruption of intracellular calcium homeostasis with different potencies. Anesthesiology. 2008;109:243-50.

Yang L, Shen Q, Xia Y, Lei X, Peng J. Sevofluraneinduced neurotoxicity is driven by OXR1 posttranscriptional downregulation involving hsamiR302e. Mol Med Rep. 2018;18:4657-65.

Yang M, Lian N, Yu Y, Wang Y, Xie K, Yu Y. Coenzyme Q10 alleviates sevoflurane induced neuroinflammation by regulating the levels of apolipoprotein $\mathrm{E}$ and phosphorylated tau protein in mouse hippocampal neurons. Mol Med Rep. 2020b;22:445-53.

Yang M, Wei H. Anesthetic neurotoxicity: apoptosis and autophagic cell death mediated by calcium dysregulation. Neurotoxicol Teratol. 2017;60:59-62.

Yang Y, Wang JZ. Nature of tau-associated neurodegeneration and the molecular mechanisms. J Alzheimers Dis. 2018;62:1305-17.

Yeh FL, Hansen DV, Sheng M. TREM2, Microglia, and neurodegenerative diseases. Trends Mol Med. 2017;23:512-33.

Yon JH, Daniel-Johnson J, Carter LB, Jevtovic-Todorovic V. Anesthesia induces neuronal cell death in the developing rat brain via the intrinsic and extrinsic apoptotic pathways. Neuroscience. 2005;135:815-27.

Yu X, Zhang F, Shi J. Neonatal exposure to sevoflurane caused cognitive deficits by dysregulating SK2 channels and GluA2-lacking AMPA receptors in juvenile rat hippocampus. Neuropharmacology. 2018;141:66-75.

Yu Y, Yang Y, Tan H, Boukhali M, Khatri A, Yu Y, Hua F, Liu L, Li M, Yang G, et al. Tau contributes to sevofluraneinduced neurocognitive impairment in neonatal mice. Anesthesiology. 2020a;133:595-610.

Yu Z, Wang J, Wang H, Wang J, Cui J, Junzhang P. Effects of sevoflurane exposure during late pregnancy on brain development and beneficial effects of enriched environment on offspring cognition. Cell Mol Neurobiol. 2020b;40:1339-52.

Zhang L, Cheng Y, Xue Z, Li J, Wu N, Yan J, Wang J, Wang C, Chen W, Zhou T, et al. Sevoflurane impairs m6Amediated mRNA translation and leads to fine motor and cognitive deficits. Cell Biol Toxicol. (2021).

Zhang L, Xue Z, Liu Q, Liu Y, Xi S, Cheng Y, Li J, Yan J, Shen $\mathrm{Y}$, Xiao $\mathrm{C}$, et al. Disrupted folate metabolism with anesthesia leads to myelination deficits mediated by epigenetic regulation of ERMN. EBioMedicine. 2019a;43:473-86.

Zhang L, Yan J, Liu Q, Xie Z, Jiang H. LncRNA Rik203 contributes to anesthesia neurotoxicity via
microRNA-101a-3p and GSK-3beta-mediated neural differentiation. Sci Rep. 2019b;9:6822.

Zhang L, Zhu B, Zeng Y, Shen H, Zhang J, Wang X. Clinical lipidomics in understanding of lung cancer: opportunity and challenge. Cancer Lett. 2020a;470:75-83.

Zhang X, Liu S, Newport GD, Paule MG, Callicott R, Thompson J, Liu F, Patterson TA, Berridge MS, Apana SM, et al. In vivo monitoring of sevoflurane-induced adverse effects in neonatal nonhuman primates using smallanimal positron emission tomography. Anesthesiology. 2016;125:133-46.

Zhang Y, Wu Z, Li X, Wan Y, Zhang Y, Zhao P. Maternal sevoflurane exposure affects differentiation of hippocampal neural stem cells by regulating miR-410-3p and ATN1. Stem Cell Res Ther. 2020b;11:423.

Zhao Y, Ai Y. Overexpression of 1ncRNA Gm15621 alleviates apoptosis and inflammation response resulting from sevoflurane treatment through inhibiting miR-133a/Sox4. J Cell Physiol. 2020;235:957-65.

Zheng H, Dong Y, Xu Z, Crosby G, Culley DJ, Zhang Y, Xie $Z$. Sevoflurane anesthesia in pregnant mice induces neurotoxicity in fetal and offspring mice. Anesthesiology. 2013;118:516-26.

Zhou B, Chen L, Liao P, Huang L, Chen Z, Liao D, Yang L, Wang J, Yu G, Wang L, et al. Astroglial dysfunctions drive aberrant synaptogenesis and social behavioral deficits in mice with neonatal exposure to lengthy general anesthesia. PLoS Biol. 2019;17:e3000086.

Zhou X, Lu D, Li WD, Chen XH, Yang XY, Chen X, Zhou $\mathrm{ZB}$, Ye JH, Feng X. Sevoflurane affects oxidative stress and alters apoptosis status in children and cultured neural stem cells. Neurotox Res. 2018;33:790-800.

Zhu G, Tao L, Wang R, Xue Y, Wang X, Yang S, Sun X, Gao G, Mao Z, Yang Q. Endoplasmic reticulum stress mediates distinct impacts of sevoflurane on different subfields of immature hippocampus. J Neurochem. 2017;142:272-85.

Zuo Y, Chang Y, Thirupathi A, Zhou C, Shi Z. Prenatal sevoflurane exposure: effects of iron metabolic dysfunction on offspring cognition and potential mechanism. Int $\mathbf{J}$ Dev Neurosci. 2021;81:1-9.

Zuo Y, Li B, Xie J, Ma Z, Thirupathi A, Yu P, Gao G, Zhou J, Zhou C, Xu H, et al. Sevoflurane anesthesia during pregnancy in mice induces cognitive impairment in the offspring by causing iron deficiency and inhibiting myelinogenesis. Neurochem Int. 2020;135:104693.

Publisher's Note Springer Nature remains neutral with regard to jurisdictional claims in published maps and institutional affiliations. 